\title{
Nanostructure-based electrochemical sensor for the voltammetric determination of benserazide, uric acid, and folic acid
}

\author{
Sakineh Esfandiari Baghbamidi a, Hadi Beitollahi ${ }^{\text {b }}$, Seyed Zia Mohammadi ${ }^{c}$, Somayeh Tajik $^{\text {d,e }}$, \\ Somayeh Soltani-Nejad a, Vahhab Soltani-Nejad ${ }^{\mathrm{f}, *}$ \\ a Islamic Azad University, Bandar Abbas Branch, Bandar Abbas, Iran \\ ${ }^{\mathrm{b}}$ Environment Department, Institute of Science and High Technology and Environmental Sciences, Graduate University of Advanced Technology, Kerman, \\ Iran \\ c Department of Chemistry, Payame Noor University, Kerman, Iran \\ d Department of Chemistry, Shahid Bahonar University of Kerman, Kerman, Iran \\ e Young Researchers Society, Shahid Bahonar University of Kerman, Kerman, Iran \\ f Department of Chemistry, Islamic Azad University, North Tehran Branch, Tehran, Iran
}

A R T I C L E I N F O

Article history:

Received 4 June 2013

Accepted 11 July 2013

Published 20 October 2013

Keywords:

Benserazide

Uric acid

Folic acid

Carbon nanotube

Carbon paste electrode

\begin{abstract}
A B S T R A C T
A carbon paste electrode modified with carbon nanotubes and ferrocene was fabricated. An electrochemical study of the modified electrode and an investigation into its efficiency for the electrocatalytic oxidation of benserazide, uric acid and folic acid were undertaken. The electrode was also used to study the electrocatalytic oxidation of benserazide using cyclic voltammetry, chronoamperometry, and square wave voltammetry (SWV). We found that the oxidation of benserazide at the surface of the modified electrode occurs at a potential about $285 \mathrm{mV}$ lower than that of unmodified carbon paste electrode. SWV gave a linear dynamic range from $8.0 \times 10^{-7}$ to $7.0 \times 10^{-4} \mathrm{~mol} / \mathrm{L}$. The detection limit was $1.0 \times 10^{-7} \mathrm{~mol} / \mathrm{L}$ for benserazide. This modified electrode was used for the determination of benserazide, uric acid, and folic acid in an urine sample.
\end{abstract}

(C) 2013, Dalian Institute of Chemical Physics, Chinese Academy of Sciences. Published by Elsevier B.V. All rights reserved.

\section{Introduction}

The integration of nanotechnology and electrochemistry is expected to produce major advances in the field of electrochemical sensors. There is growing interest in developing new enhanced materials and designing novel sensors with controlled features on a nanometric scale. The unique properties of metal nanoparticles (enhanced mass transport, high surface area, and improved signal-to-noise ratio) can often be advantageous in electroanalytical techniques [1,2]. Carbon nanotubes (CNTs) are gaining popularity in electrochemistry as a viable nanomaterial because of their extraordinary electronic, chemical, and structural characteristics. CNTs display intrinsic prop- erties that include high surface areas, high electrical conductivities, and their inherent size and hollow geometry, which make them extremely attractive as substrates for heterogeneous catalysis [3-16].

Benserazide (BZ, Scheme 1(a)) is used with levodopa for the treatment of Parkinson's disease [17-19]. BZ is an irreversible inhibitor of peripheral aromatic L-amino acid decarboxylase (AADC). BZ at the recommended therapeutic dose does not cross the blood-brain barrier to any significant degree, and combination therapy with levodopa reduces the amount of levodopa required for optimal therapeutic benefit and permits an earlier response to therapy [20]. BZ is rapidly absorbed after oral administration, and it is metabolized to trihydroxy benzyl

*Corresponding author. Tel: +98-77009827; Fax: +91-77009829; E-mail: soltani.vahhab@gmail.com DOI: 10.1016/S1872-2067(12)60655-X | http://www.sciencedirect.com/science/journal/18722067 | Chin. J. Catal., Vol. 34, No. 10, October 2013 
<smiles>NC(CO)C(=O)NNCc1ccc(O)c(O)c1O</smiles>

(a)<smiles>O=c1[nH]c(=O)c2[nH]c(=O)[nH]c2[nH]1</smiles>

(b)<smiles>Nc1nc2ncc(CNc3ccc(C(=O)NC(CCC(=O)O)C(=O)O)cc3)nc2c(=O)[nH]1</smiles>

(c)

Scheme 1. Structures of benserazide (a), uric acid (b), and folic acid (c).

hydrazine [21]. Several methods have been used for the determination of BZ in pharmaceutical preparations such as capillary electrophoresis [22], spectrophotometry [23], high performance liquid chromatography [24], chemiluminescence [25], and voltammetry [26-28].

Uric acid (UA, Scheme 1(b)) is the final product of purine metabolism in the human body [29]. Continuous monitoring of UA in body fluid is essential because abnormal concentration levels can lead to several diseases such as hyperuricaemia and gout [29]. Several methods for the determination of UA have been described in the literature including chemiluminescence and enzymatic spectrophotometry. However, most of these methods are complicated because they need derivatization or the combination of various detection methods. It is thus desirable to have a simple and direct method such as an electrochemical technique to monitor the concentration of UA in biological fluids [30-38].

Folic acid (FA, Scheme 1(c)) is a significant component of the haematopoietic system and is the coenzyme that controls the generation of ferrohaeme [39]. A decrease in the concentration of FA in body fluids leads to several complications including gigantocytic anaemia, leucopoenia, devolution of mentality, psychosis, and an increased possibility of heart attack and stroke [40]. It has also been suggested that a decreased folate concentration is associated with enhanced carcinogenesis as FA with vitamin $\mathrm{B}_{12}$ participates in nucleotide synthesis, cell division, and gene expression. Periconceptual supplementation of FA has been demonstrated to significantly reduce the incidence and recurrence of neural tube defects such as spina bifida in women. The normal concentration of FA in human blood serum is $34.4 \pm 10.4 \mathrm{nmol} / \mathrm{L}$. Therefore, the sensitive determination of FA is very important from a clinical point of view. Numerous methods have been used for the quantification of FA including spectrophotometry, flow injection chemiluminescence, fluorometry, high-performance liquid chromatography, and electrochemical methods. Among the different detection methods, electrochemical methods have received much attention in recent years because they are less expensive, more convenient, more selective and sensitive [41-49].

In this work we describe the preparation of a new electrode composed of carbon nanotube paste electrode(CNPE) modified with ferrocene (FCCNPE) and investigate its performance in the electrocatalytic determination of BZ in aqueous solutions. We also evaluate the analytical performance of the modified electrode for the quantification of BZ in the presence of UA and FA.

\section{Experimental}

\subsection{Apparatus and chemicals}

Electrochemical measurements were performed with an Autolab potentiostat/galvanostat (PGSTAT 302 N, Eco Chemie, Netherlands). Experimental conditions were controlled with General Purpose Electrochemical System (GPES) software. A conventional three electrode cell was used at $25 \pm 1{ }^{\circ} \mathrm{C}$. A $\mathrm{Ag} / \mathrm{AgCl} / \mathrm{KCl}$ (3.0 mol/L) electrode, a platinum wire, and FCCNPE were used as the reference, auxiliary, and working electrodes, respectively. A Metrohm 691 pH/Ion meter was used for $\mathrm{pH}$ measurements.

All solutions were freshly prepared with double distilled water. BZ, UA, FA, and all other reagents were of analytical grade from Merck (Darmstadt, Germany). Graphite powder and paraffin oil (DC 350, density $=0.88 \mathrm{~g} / \mathrm{cm}^{3}$ ) were used as binding agents (both from Merck) to prepare the pastes. Multiwalled carbon nanotubes (purity more than 95\%) with an o.d. between 10 and $20 \mathrm{~nm}$, an i.d. between 5 and $10 \mathrm{~nm}$, and a tube length from 0.5 to $200 \mu \mathrm{m}$ were purchased from Nanostructured \& Amorphous Materials, Inc. Buffer solutions were prepared using orthophosphoric acid and its salts to give a $\mathrm{pH}$ range of 2.0-11.0.

\subsection{Preparation of the electrodes}

The FCCNPEs were prepared by hand mixing $0.01 \mathrm{~g}$ of ferrocene (FC) with $0.89 \mathrm{~g}$ graphite powder and $0.1 \mathrm{~g}$ CNTs with a mortar and pestle. Then, ca. $0.7 \mathrm{~mL}$ of paraffin oil was added to the mixture and mixed for 20 min until a uniform wet paste was obtained. The paste was then packed into the end of a glass tube (ca. $3.4 \mathrm{~mm}$ i.d. and $15 \mathrm{~cm}$ long). A copper wire was inserted into the carbon paste; this provided the electrical contact. When necessary, a new surface was obtained by pushing excess paste out of the tube and polishing with weighing paper. For comparison, a FC modified CPE electrode (FCCPE) without CNTs, a CNTs paste electrode (CNPE) without FC, and unmodified CPE without FC or CNTs were also prepared in the same way.

\section{Results and discussion}

\subsection{Electrochemical behavior of FCCNPE}

Cylic voltammetry (CV) was used to study the electrochemical behavior of FCCNPE. Experimental results show that well-defined and reproducible anodic and cathodic peaks related to the ferrocene/ferricenium $\left(\mathrm{Fc} / \mathrm{Fc}^{+}\right)$redox system with 
Table 1

Cyclic voltammetric data obtained for FCCNPE in $0.1 \mathrm{~mol} / \mathrm{L} \mathrm{PBS} \mathrm{(pH} \mathrm{7.0)} \mathrm{at} 10 \mathrm{~m} \mathrm{V/s.}$

\begin{tabular}{cccccc}
\hline$E_{\mathrm{pa}} \mathrm{a} / \mathrm{V}$ & $E_{\mathrm{pc}} / \mathrm{V}$ & $E_{1 / 2} / \mathrm{V}$ & $\Delta E_{\mathrm{p}} / \mathrm{V}$ & $I_{\mathrm{pa}} / \mu \mathrm{A}$ & $I_{\mathrm{pc}} / \mu \mathrm{A}$ \\
\hline $0.365 \pm 1.1 \mathrm{~b}$ & $0.26 \pm 1.2$ & $0.312 \pm 1.4$ & $0.105 \pm 1.2$ & $1.34 \pm 1.3$ & $1.0 \pm 1.6$ \\
\hline
\end{tabular}

a Versus $\mathrm{Ag} / \mathrm{AgCl} / \mathrm{KCl}(3.0 \mathrm{~mol} / \mathrm{L})$ as the reference electrode.

${ }^{\mathrm{b}}$ All the ' \pm ' values are RSD\% $(n=5)$.

quasi-reversible behavior in an aqueous medium were obtained [50]. The electrode's capability to generate a reproducible surface was examined by $\mathrm{CV}$ in an optimum solution $\mathrm{pH}$ of 7.0 using five separately prepared FCCNPEs (Table 1). Calculated RSDs for various parameters were used as criteria for satisfactory surface reproducibility (about 1\%-4\%), which is virtually the same as that expected for a renewed or an ordinary carbon paste surface [13]. However, we regenerated the surface of FCCNPE before each experiment as previously described [13].

Additionally, the long term stability of FCCNPE was evaluated over a three-week period. When CVs were recorded after the modified electrode was stored in an air atmosphere at room temperature the peak potential of BZ oxidation was unchanged and the current signals showed a less than $2.7 \%$ decrease relative to the initial response. The antifouling properties of the modified electrode toward BZ oxidation and its oxidation products in the presence of $\mathrm{BZ}$ were investigated by recording $\mathrm{CVs}$ of the modified electrode before and after use. CVs were recorded in the presence of BZ after 15 potential cycles at a scan rate of $10 \mathrm{mV} / \mathrm{s}$. The peak potentials were unchanged and the currents decreased by less than $2.5 \%$. Therefore, at the surface of FCCNPE the sensitivity increases and the fouling effect of the analyte and its oxidation product decreases.

\subsection{Influence of $p H$}

The electrochemical behavior of $\mathrm{BZ}$ is dependent on the $\mathrm{pH}$ value of the aqueous solution whereas the electrochemical properties of the $\mathrm{Fc} / \mathrm{Fc}^{+}$redox couple are independent of $\mathrm{pH}$. Therefore, $\mathrm{pH}$ optimization of the solution is necessary for the electrocatalytic oxidation of BZ. The electrochemical behavior of $\mathrm{BZ}$ was thus studied in $0.1 \mathrm{~mol} / \mathrm{L}$ PBS at different $\mathrm{pH}$ values $(2.0<\mathrm{pH}<11.0)$ at the surface of FCCNPE by CV. We found that the electrocatalytic oxidation of BZ at the surface of FCCNPE was more favoured under neutral conditions than in acidic or basic media. This came from the gradual growth of the anodic peak current and a simultaneous decrease in the cathodic peak current in the cyclic voltammograms obtained at the surface of FCCNPE. The variation of $I_{\mathrm{pa}}$ as a function of $\mathrm{pH}$ was also investigated. Results show that the anodic peak current and the displaced potential of BZ electrooxidation are high at a $\mathrm{pH}$ of 7.0. A pH of 7.0 was thus chosen as the optimum pH for the electrocatalysis of BZ oxidation at the surface of FCCNPE.

\subsection{Electrocatalytic oxidation of BZ with FCCNPE}

Figure 1 shows $\mathrm{CV}$ responses for the electrochemical oxidation of $0.3 \mathrm{mmol} / \mathrm{L} \mathrm{BZ}$ for unmodified CPE, CNPE, FCCPE, and FCCNPE. While the anodic peak potentials for BZ oxidation for
CNPE and unmodified CPE are 610 and $650 \mathrm{mV}$, respectively, the corresponding potentials for FCCNPE and FCDCPE are ca. $365 \mathrm{mV}$. These results indicate that the peak potential for $\mathrm{BZ}$ oxidation for the FCCNPE and FCDCPE electrodes shift negatively by ca. 245 and $285 \mathrm{mV}$ compared to CNPE and unmodified CPE, respectively. However, FCCNPE gave a far higher anodic peak current for the oxidation of $\mathrm{BZ}$ compared with FCDCPE, indicating that the combination of CNTs and the mediator (FCD) significantly improves the performance of the electrode toward BZ oxidation. In fact, FCCNPE in the absence of BZ exhibited a well-behaved redox reaction (Fig. 1(3)) in 0.1 mol/L PBS ( $\mathrm{pH} 7.0$ ). However, there was a drastic increase in the anodic peak current in the presence of $0.3 \mathrm{mmol} / \mathrm{L} \mathrm{BZ}$.

Based on these results we propose an EC' catalytic mechanism as shown in Scheme 2 to describe the electrochemical oxidation of BZ at the FCCNPE. In this scheme, BZ is oxidized in the catalytic reaction by the oxidized form of $\mathrm{FC}$ that is produced at the electrode surface by an electrochemical reaction.

The effect of scan rate on the electrocatalytic oxidation of BZ at the FCCNPE was investigated by linear sweep voltammetry (LSV) (Fig. 2(a)). A plot of peak height ( $\left.I_{\mathrm{p}}\right)$ vs the square root of scan rate $\left(v^{1 / 2}\right)$ was found to be linear in the range of $2.5-40$ $\mathrm{mV} / \mathrm{s}$, suggesting that at sufficient overpotential the process is diffusion rather than surface controlled (Fig. 2(b)) [50]. A plot of the scan rate-normalized current $\left(I_{\mathrm{p}} / v^{1 / 2}\right)$ vs the scan rate (Fig. 2(c)) exhibits the characteristic shape typical of an EC' process [50].

The Tafel slope (b) can be obtained from the slope of $E_{\mathrm{p}}$ vs $\log v$ using Eq. (1) [50]:

$$
E_{\mathrm{p}}=b / 2 \log v+\text { constant }
$$

The Tafel slope was found to be $82.0 \mathrm{mV}$ (Fig. 2(d)), which

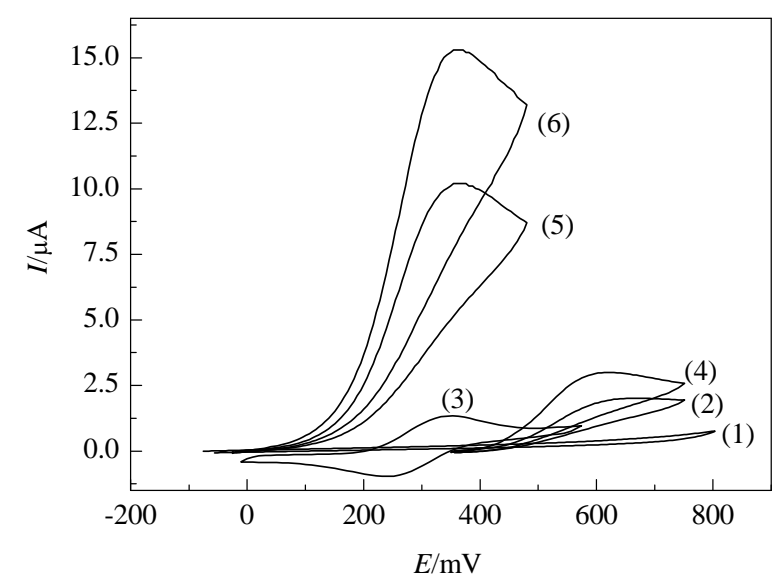

Fig. 1. CVs of unmodified CPE in $0.1 \mathrm{~mol} / \mathrm{L}$ PBS ( $\mathrm{pH}$ 7.0) (1), unmodified CPE in $0.3 \mathrm{mmol} / \mathrm{L} \mathrm{BZ} \mathrm{(2),} \mathrm{FCCNPE} \mathrm{in} 0.1 \mathrm{~mol} / \mathrm{L}$ PBS (3), CNPE in 0.3 $\mathrm{mmol} / \mathrm{L} \mathrm{BZ} \mathrm{(4),} \mathrm{FCCPE} \mathrm{in} 0.3 \mathrm{mmol} / \mathrm{L} \mathrm{BZ} \mathrm{(5),} \mathrm{and} \mathrm{FCCNPE} \mathrm{in} 0.3$ $\mathrm{mmol} / \mathrm{L} \mathrm{BZ} \mathrm{(6).} \mathrm{In} \mathrm{all} \mathrm{cases} \mathrm{the} \mathrm{scan} \mathrm{rate} \mathrm{was} 10 \mathrm{mV} / \mathrm{s}$. 


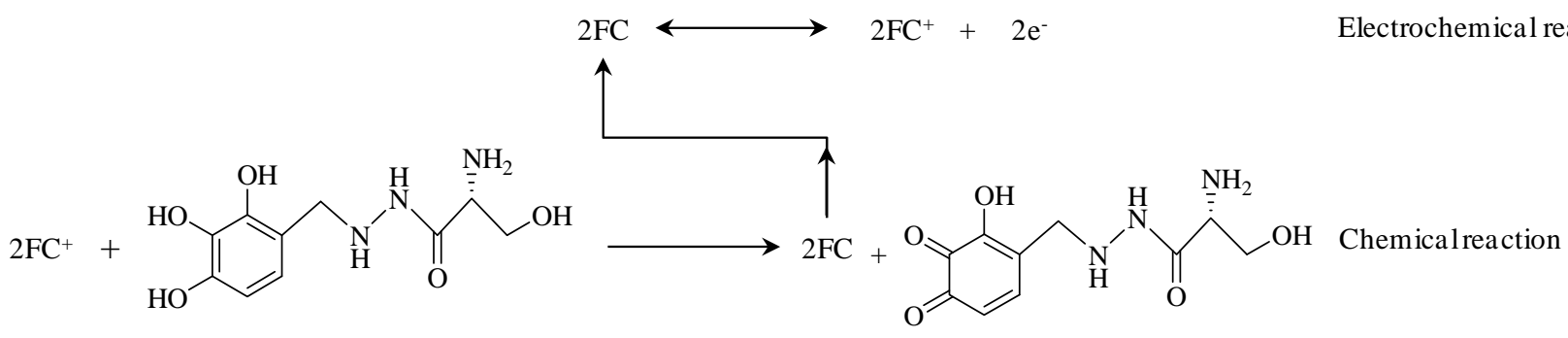

Scheme 2. Electrocatalytic oxidation of BZ at the FCCNPE.

indicates that a one-electron transfer process is the rate limiting step assuming a transfer coefficient $(a)$ of about 28.0.

\subsection{Chronoamperometric measurements}

Chronoamperometric measurements of BZ at the FCCNPE were carried out by setting the working electrode potential to $0.45 \mathrm{~V}$ (first potential step) and $0.1 \mathrm{~V}$ (second potential step) for various concentrations of BZ in PBS (pH 7.0) (Fig. 3).

For an electroactive material (BZ in this case) with a diffusion coefficient of $D$ the current observed for the electrochemical reaction at the mass transport limited condition is described by the Cottrell equation [50]. Experimental plots of $I$ vs $t^{-1 / 2}$ were used with the best fits for different concentrations of BZ (Fig. 3(a)). The slopes of the resulting straight lines were then plotted against the BZ concentration (Fig. 3(b)). From the resulting slope and the Cottrell equation the mean value of $D$ was
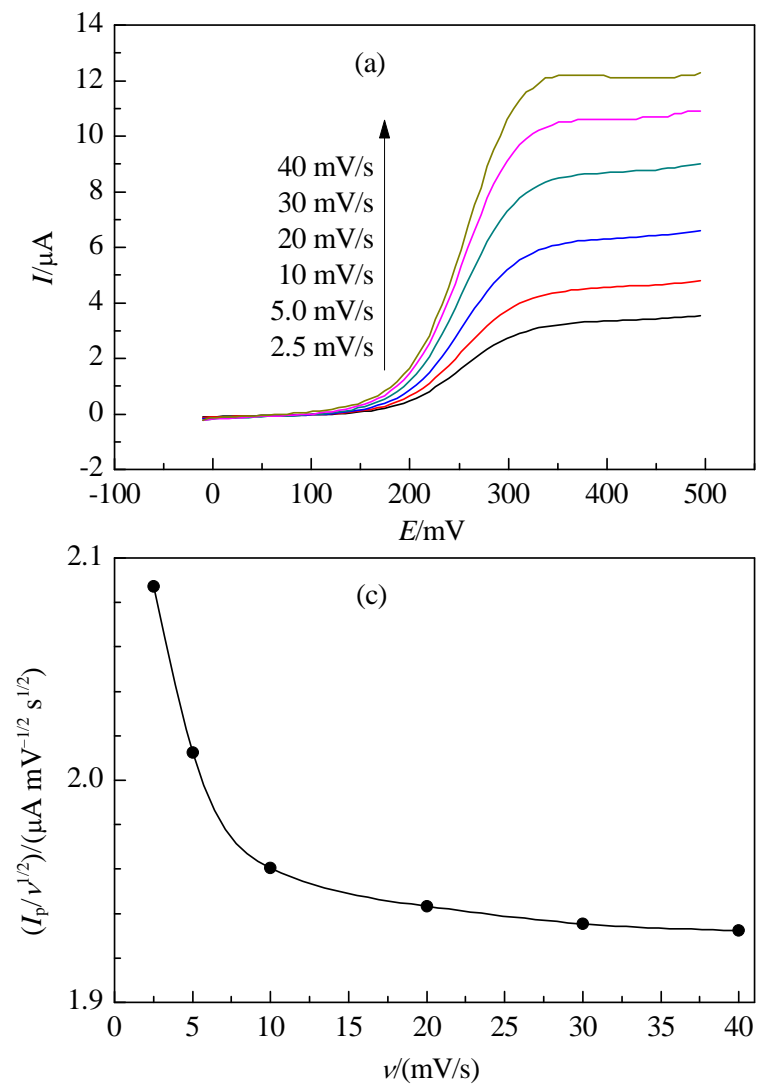

found to be $5.14 \times 10^{-6} \mathrm{~cm}^{2} / \mathrm{s}$.

\subsection{Electrocatalytic determination of $B Z, U A$, and $F A$}

The electrocatalytic peak current of BZ oxidation at the surface of the modified electrode can be used for the determination of BZ in solution. Therefore, square wave voltammetry (SWV) experiments were performed using modified electrodes in phosphate buffer solutions containing various concentrations of BZ. The mediated oxidation peak currents of BZ at the surface of the modified electrode were proportional to the concentration of BZ within 0.8 to $700.0 \mu \mathrm{mol} / \mathrm{L}$ in SWV. The regression equation was $I(\mu \mathrm{A})=0.424 C(\mu \mathrm{mol} / \mathrm{L})+2.627\left(R^{2}\right.$ $=0.999)$. The detection limit $(3 \sigma)$ was $0.1 \mu \mathrm{mol} / \mathrm{L}$. The regression equation for $\mathrm{UA}$ in the range of $15.0-1000.0 \mu \mathrm{mol} / \mathrm{L}$ was $I$ $(\mu \mathrm{A})=0.032 C(\mu \mathrm{mol} / \mathrm{L})+6.8\left(R^{2}=0.996\right)$ and the detection limit was $10.0 \mu \mathrm{mol} / \mathrm{L}$. The regression equation for $\mathrm{FA}$ in the
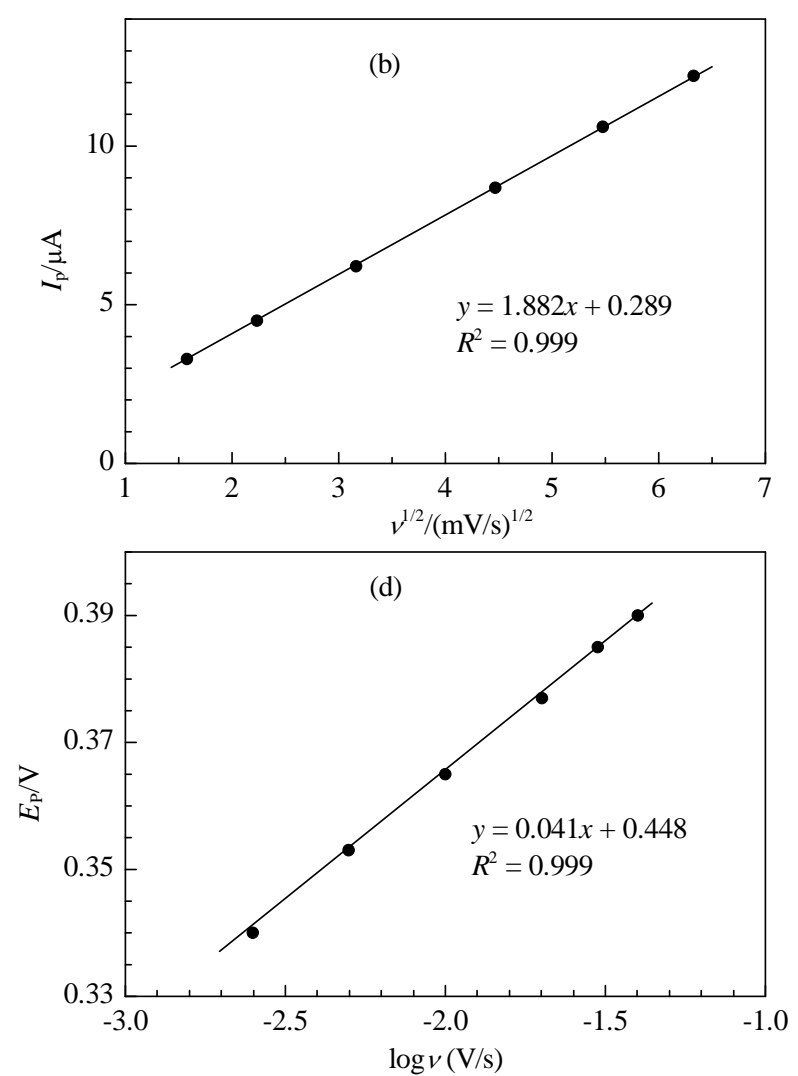

Fig. 2. (a) LSVs of FCCNPE in $0.1 \mathrm{~mol} / \mathrm{L}$ PBS (pH 7.0) containing $100.0 \mu \mathrm{mol} / \mathrm{L} \mathrm{BZ}$ at various scan rates; (b) Variation of anodic peak current vs $v^{1 / 2}$; (c) Normalized current $\left(I_{\mathrm{p}} / v^{1 / 2}\right)$ vs $v$; (d) Anodic peak potential vs $\log v$. 

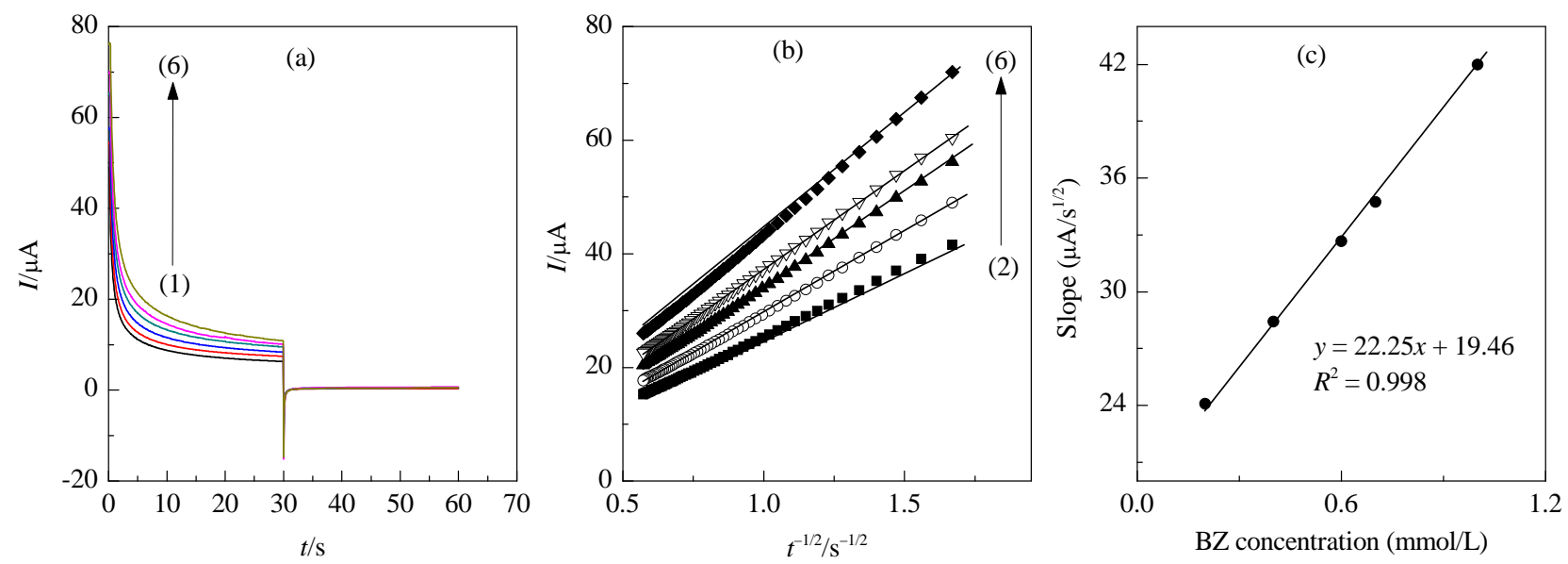

Fig. 3. (a) Chronoamperograms obtained at the FCCNPE in $0.1 \mathrm{~mol} / \mathrm{L}$ PBS (pH 7.0) for different concentrations of BZ, where (1)-(6) correspond to 0.0, $0.2,0.4,0.6,0.7$, and $1.0 \mathrm{mmol} / \mathrm{L} \mathrm{BZ}$, respectively; (b) Plots of $I$ vs $t^{-1 / 2}$ obtained from chronoamperograms (2)-(6); (c) Plot of the slope of the straight lines against $\mathrm{BZ}$ concentration.

range of $20.0-1200.0 \mu \mathrm{mol} / \mathrm{L}$ was $I(\mu \mathrm{A})=0.021 C(\mu \mathrm{mol} / \mathrm{L})+$ $5.2\left(R^{2}=0.998\right)$ and the detection limit was $15.0 \mu \mathrm{mol} / \mathrm{L}$.

\subsection{Simultaneous determination of $B Z, U A$, and FA}

To the best of our knowledge no report exists on the simultaneous determination of BZ, UA, and FA using the FCCNPE. Therefore, the main objective of this study was to detect BZ, UA,
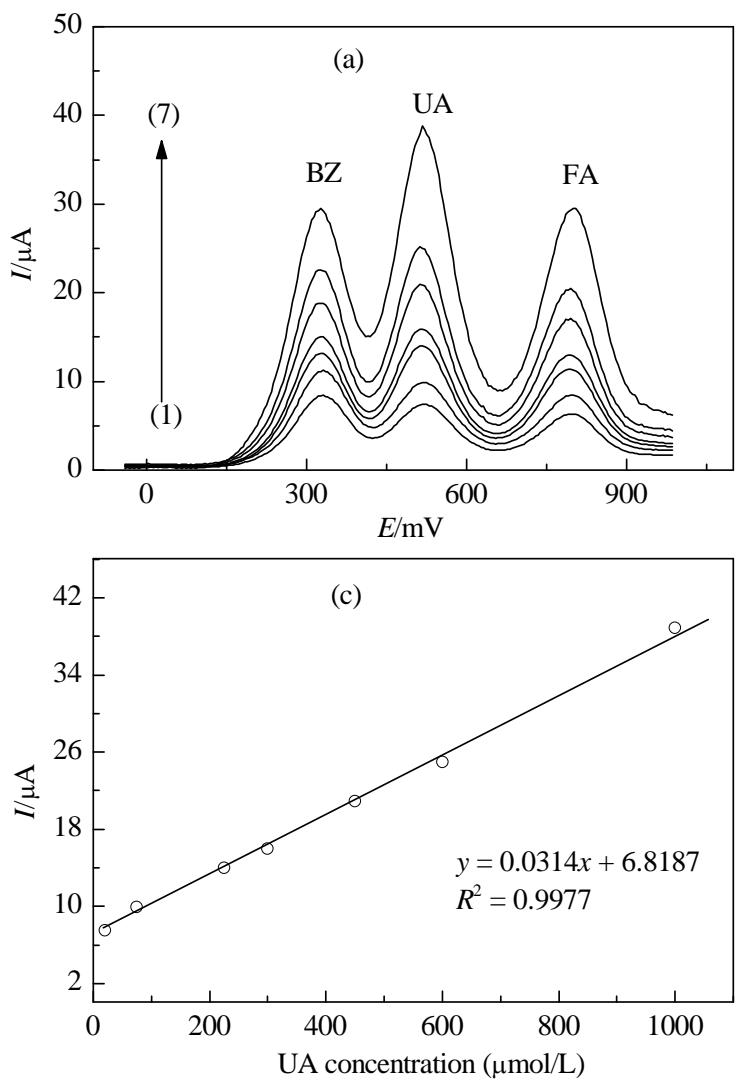

and FA simultaneously using the FCCNPE. This was performed by simultaneously changing the concentrations of BZ, UA, and FA and recording their SWVs. Voltammetric results show well-defined anodic peaks at potentials of 340,530, and 810 $\mathrm{mV}$, corresponding to the oxidation of BZ, UA, and FA, respectively. These results indicate that the simultaneous determination of these compounds is feasible at the FCCNPE, as shown in Fig. 4 .
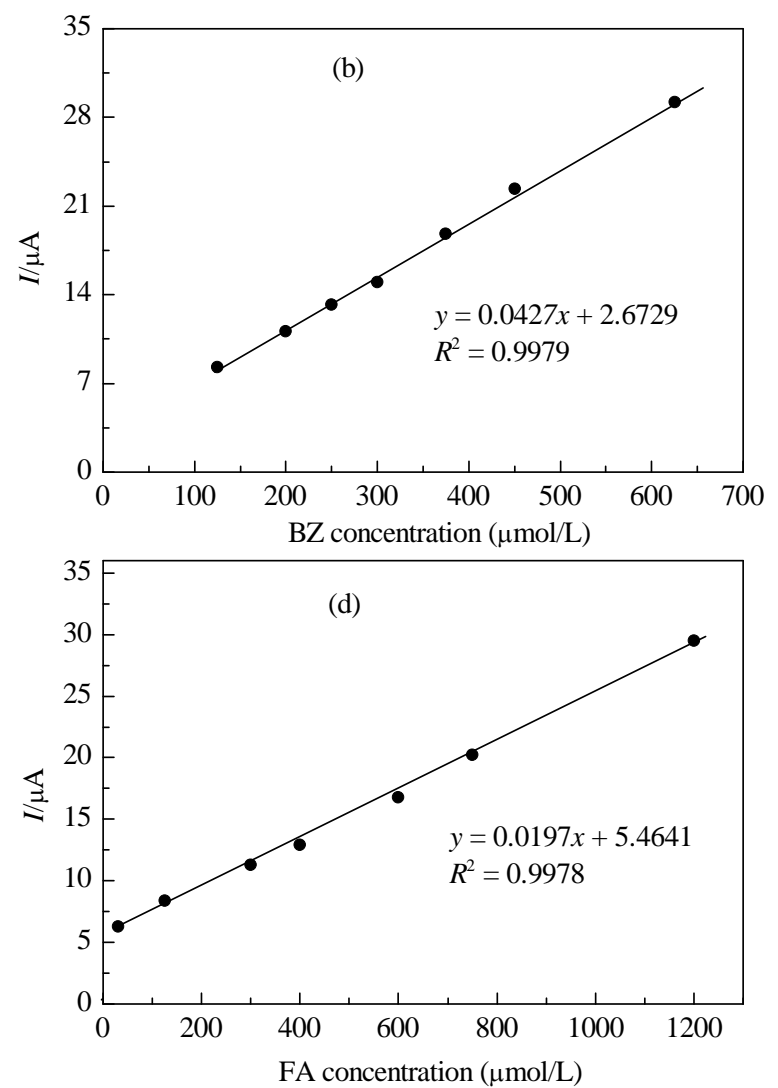

Fig. 4. (a) SWVs of the FCCNPE in $0.1 \mathrm{~mol} / \mathrm{L}$ PBS (pH 7.0) containing different concentrations of BZ+UA+FA ( $\mu$ mol/L). (1) 125.0+20.0+30.0; (2) 200.0+75.0+125.0; (3) 250.0+225.0+300.0; (4) 300.0+300.0+400.0; (5) 375.0+450.0+600.0; (6) 450.0+600.0+750.0; (7) 625.0+1000.0+1200.0; (b), (c), and (d) are plots of $I_{\mathrm{p}}$ vs BZ, UA, and FA concentrations, respectively. 


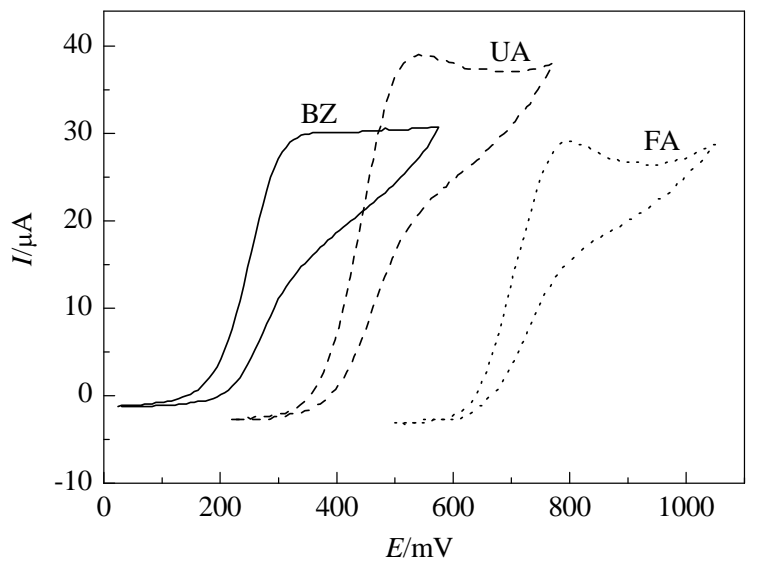

Fig. 5. CVs of the FCCNPE in $0.1 \mathrm{~mol} / \mathrm{L}$ PBS (pH 7.0) containing 0.6 $\mathrm{mmol} / \mathrm{L} \mathrm{BZ}, 1 \mathrm{mmol} / \mathrm{L} \mathrm{UA}$, and $1.2 \mathrm{mmol} / \mathrm{L} \mathrm{FA}$.

Additionally, Fig. 5 shows CVs of BZ, UA, and FA at the surface of the modified electrode. It shows that their peak potentials are well separated.

\subsection{Interference studies}

The influences of various substances that could potentially interfere with the determination of BZ were studied under optimum conditions using $50.0 \mu \mathrm{mol} / \mathrm{L} \mathrm{BZ}$ at a pH of 7.0. Potential interfering substances were chosen from a group of substances commonly found with BZ in pharmaceuticals and/or in biological fluids. The tolerance limit was defined as the maximum concentration of the interfering substance that caused an error of less than $\pm 5 \%$ in the determination of BZ. According to the results, an 800-fold excess of glucose, sucrose, lactose, fructose, and citric acid, a 600-fold excess of methanol, ethanol, $\mathrm{Ca}^{2+}$, $\mathrm{Mg}^{2+}, \mathrm{SO}_{4}{ }^{2-}, \mathrm{Al}^{3+}, \mathrm{NH}_{4}{ }^{+}, \mathrm{Fe}^{2+}, \mathrm{Fe}^{3+}, \mathrm{CO}_{3}{ }^{2-}, \mathrm{Cl}^{-}$, and $\mathrm{F}^{-}$, as well as a 200-fold excess of alanine, methionine, phenylalanine, glycine, uric acid, and folic acid (vitamin B9) did not affect the selectivity toward BZ. Additionally, neither a saturated starch solution nor a 50-fold excess of urea interfered with the determination of BZ. Although ascorbic acid did interfere, this interference could be minimized by adding ascorbic oxidase enzyme, which exhibits a high selectivity toward the oxidation of ascorbic acid. Levodopa, carbidopa, epinephrine, and norepinephrine did, however, interfere with the determination of BZ.

\subsection{Real sample analysis}

To evaluate the applicability of the proposed method to real samples we determined the concentrations of BZ, UA, and FA in an urine sample. The BZ, UA, and FA contents were determined after sample preparation using the standard addition method. The results are given in Table 2 .

\section{Conclusions}

We constructed a chemically modified carbon paste electrode using multiwalled carbon nanotubes and ferrocene as modifying species. The electrochemical behavior of $\mathrm{BZ}$ was studied by cyclic voltammetry. The results showed that the oxidation of BZ is catalyzed at a pH of 7.0 and the peak potential of BZ shifted to a less positive potential by $285 \mathrm{mV}$ at the surface of the modified electrode. The modified electrode was highly selective in voltammetric measurements of BZ, UA, and FA. Finally, the modified electrode was used for the determination of BZ, UA, and FA in a urine sample.

\section{References}

[1] Campbell F W, Compton R G. Anal Bioanal Chem, 2010, 396: 241

[2] Wildgoose G G, Banks C E, Compton R G. Small, 2006, 2: 182

[3] Beitollahi H, Sheikhshoaie I. Mater Sci Eng C, 2012, 32: 375

[4] Habibi B, Abazari M, Pournaghi-Azar M H. Chin J Catal (催化学报), 2012, 33: 1783

[5] Beitollahi H, Mohadesi A, Mohammadi S, Akbari A. Electrochim Acta, 2012, 68: 220

[6] Ensafi A A, Bahrami H, Karimi-Maleh H, Mallakpour S. Chin J Catal (催化学报), 2012, 33: 1919

[7] Beitollahi H, Karimi-Maleh H, Khabazzadeh H. Anal Chem, 2008, 80: 9848

[8] Ensafi A A, Lotfi M, Karimi-Maleh H. Chin J Catal (催化学报), 2012, 33: 487

[9] Ahmadipour M, Taher M A, Beitollahi H, Hosseinzadeh R. Chin Chem Lett, 2012, 23: 981

[10] Li W Y, Liu J G, Yan C W. J Solid State Electrochem, 2013, 17: 1369

[11] Beitollahi H, Mohadesi A, Khalilizadeh Mahani S, Karimi-Maleh H, Akbari A. Ionics, 2012, 18: 703

[12] Adekunle A S , Ozoemena K I, Agboola B O. J Solid State Electrochem, 2013, 17: 1311

[13] Beitollahi H, Raoof J B, Hosseinzadeh R. Talanta, 2011, 85: 2128

[14] Beitollahi H, Khabazzadeh H, Karimi-Maleh H, Akbari A. Chin Chem Lett, 2012, 23: 719

[15] Dogan-Topal B.J Solid State Electrochem, 2013, 17: 1059

[16] Beitollahi H, Mohammadi S. Chin J Catal (催化学报), 2013, 34: 1098

[17] Calne D B, Sandler M. Nature, 1970, 226: 21

[18] Olanow C W, Tatton W G. Ann Rev Neurosci, 1999, 22: 123

[19] Zhao K J. In: Zhongguo Huaxue Yaopin Daquan (An Encyclopaedia

Table 2

Application of the FCCNPE to the simultaneous determination of BZ, UA, and FA in urine.

\begin{tabular}{|c|c|c|c|c|c|c|c|c|c|c|c|}
\hline \multicolumn{3}{|c|}{ Spiked $(\mu \mathrm{mol} / \mathrm{L})$} & \multicolumn{3}{|c|}{ Found $(\mu \mathrm{mol} / \mathrm{L})$} & \multicolumn{3}{|c|}{ Recovery (\%) } & \multicolumn{3}{|c|}{ RSD (\%) } \\
\hline $\mathrm{BZ}$ & UA & FA & $\mathrm{BZ}$ & UA & FA & $\mathrm{BZ}$ & UA & FA & $\mathrm{BZ}$ & UA & FA \\
\hline 0 & 0 & 0 & ND & ND & ND & - & - & - & - & - & - \\
\hline 2.5 & 10.0 & 25.0 & 2.4 & 10.1 & 25.5 & 96.0 & 101.0 & 102.0 & 1.3 & 3.3 & 2.1 \\
\hline 7.5 & 15.0 & 35.0 & 7.6 & 14.6 & 34.5 & 101.3 & 97.3 & 98.6 & 1.9 & 2.8 & 2.9 \\
\hline 12.5 & 20.0 & 45.0 & 12.3 & 19.7 & 45.3 & 98.4 & 98.5 & 100.7 & 3.1 & 2.2 & 2.3 \\
\hline 17.5 & 25.0 & 55.0 & 17.9 & 25.2 & 53.8 & 102.3 & 100.8 & 97.8 & 2.9 & 1.8 & 3.4 \\
\hline
\end{tabular}

ND: Not detected. 


\section{Graphical Abstract}

Chin. J. Catal., 2013, 34: 1869-1875 doi: 10.1016/S1872-2067(12)60655-X

\section{Nanostructure-based electrochemical sensor for the voltammetric determination of benserazide, uric acid, and folic acid}

Sakineh Esfandiari Baghbamidi, Hadi Beitollahi, Seyed Zia Mohammadi, Somayeh Tajik, Somayeh Soltani-Nejad, Vahhab Soltani-Nejad* Islamic Azad University, Iran; Graduate University of Advanced Technology, Iran; Payame Noor University, Iran;

Shahid Bahonar University of Kerman, Iran
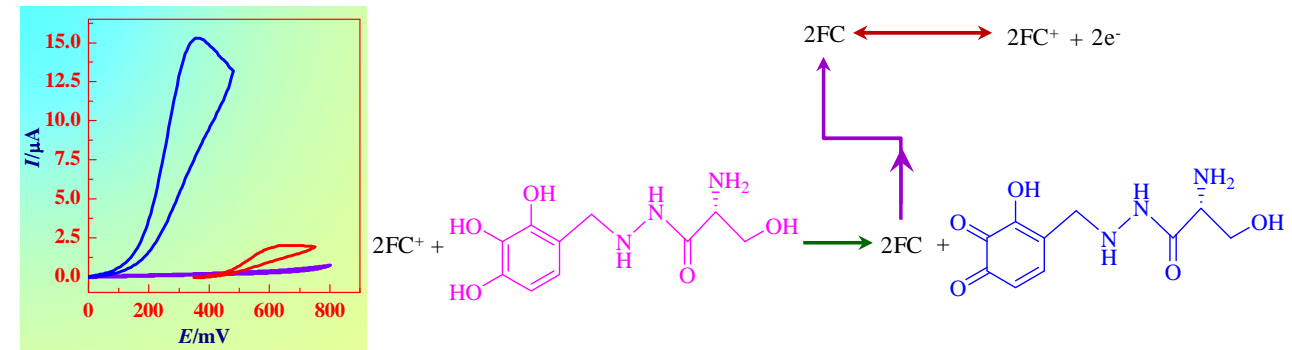

Electrochemical reaction

A new electrochemical sensor based on a ferrocene (FC) modified carbon nanotube paste electrode was constructed for the simultaneous determination of benserazide, uric acid, and folic acid.

of Chinese Chemicals, in Chinese). Beijing: New Time Press, 1999

[20] Treseder S A, Rose S, Summo L, Jenner P. J Neural Transm, 2003, 110: 229

[21] In: Sweetman S C (Ed). Martindale: The Complete Drug Reference. 34th ed. London: Pharmaceutical Press, 2005

[22] Blanco-Lopez M C, Lobo-Castanon M J, Ordieres A J M, TunonBlanco P. Electroanalysis, 2007, 19: 207

[23] Karpińska J, Smyk J, Wołyniec E. Spectrochim Acta Part A, 2005, 62: 213

[24] Wang J, Zhou Y, Liang J, He P G, Fang Y Z. Chromatographia, 2005, 61: 265

[25] Lu J Q, He W W, Zhou X W. Chin Chem Lett, 2006, 17: 1233

[26] Wabaidur S M, Alam S M, Khan M A, Lee S H. Appl Chem, 2008, 12: 85

[27] Pérez-Ortiz M, Bollo S, Zapata-Urzúa C, Yáñez C, Álvarez-Lueje A. Anal Lett, 2011, 44: 1683

[28] Ensafi A A, Bahrami H, Rezaei B, Karimi-Maleh H. Mater Sci Eng C, 2013, 33: 831

[29] Popa E, Kubota Y, Tryk D A, Fujishima A. Anal Chem, 2000, 72: 1724

[30] Beitollahi H, Raoof J B, Hosseinzadeh R. Electroanalysis, 2011, 23: 1934

[31] Huo J E, Shangguan E B, Li Q M. Electrochim Acta, 2013, 89: 600

[32] Beitollahi H, Sheikhshoaie I. Electrochim Acta, 2011, 56: 10259

[33] Bi H Q Li Y H, Liu S F, Guo P Z, Wei Z B, Lü C X, Zhang J Z, Zhao X S. Sens Actuators B, 2012, 171-172: 1132

[34] Vulcu A, Grosan C, Muresan L M, Pruneanu S, Olenic L. Electrochim Acta, 2013, 88: 839
[35] Beitollahi H, Raoof J B, Karimi-Maleh H, Hosseinzadeh R. J Solid State Electrochem, 2012, 16: 1701

[36] Zheng X Y, Zhou X C, Ji X Y, Lin R Y, Lin W X. Sens Actuators B, 2013, 178: 359

[37] Beitollahi H, Sheikhshoaie I. Anal Methods, 2011, 3: 1810

[38] Shi P Y, Miao X Q, Yao H, Lin S J, Wei B Y, Chen J J, Lin X H, Tang Y H. Electrochim Acta, 2013, 92: 341

[39] The Merck Index. 12th ed. New York: Merck, 1996

[40] Wei S H, Zhao F Q Xu Z Y, Zeng B Z. Microchim Acta, 2006, 152: 285

[41] Beitollahi H, Sheikhshoaie I.J Electroanal Chem, 2011, 661: 336

[42] Bandžuchová L, Šelešovská R, Navrátil T, Chýlková J. Electrochim Acta, 2011, 56: 2411

[43] Beitollahi H, Raoof J B, Hosseinzadeh R. Anal Sci, 2011, 27: 991

[44] Zhao K, Zhao L, He Y, Cai Y, Tian D M, Zang S L, Zhang Y Y. J Electroanal Chem, 2012, 677-680: 105

[45] Beitollahi H, Mohadesi A, Mohammadi S, Pahlavan A, Karimi-Maleh H, Akbari A. J Mol Liq, 2012, 169: 130

[46] Prasad B B, Madhuri R, Tiwari M P, Sharma P S. Sens Actuators B, 2010, 146: 321

[47] Beitollahi H, Taher M A, Mirrahimi F, Hosseinzadeh R. Mater Sci Eng C, 2013, 33: 1078

[48] Weng J, Zhang Z W, Sun L P, Wang J A. Biosens Bioelectron, 2011, 26: 1847

[49] Rastakhiz N, Beitollahi H, Kariminik A, Karimi F. J Mol Liq, 2012, 172: 66

[50] Bard A J, Faulkner L R. Electrochemical Methods Fundamentals and Applications. 2nd ed. New York: Wiley, 2001 